\title{
The application of barbed suture during the partial nephrectomy may modify perioperative results: a systematic review and meta-analysis
}

\author{
Yifei $\mathrm{Lin}^{1+}$, Banghua Liao ${ }^{1+}$, Sike Lai ${ }^{2}$, Jin Huang ${ }^{3^{*}} \mathbb{D}$, Liang Du${ }^{3^{*}}$, Kunjie Wang ${ }^{1 *}$ and Hong $\mathrm{Li}^{1}$
}

\begin{abstract}
Background: Barbed sutures can avoid knot tying and speed the suture placement in the PN(partial nephrectomy). On account of the impact on clinical outcomes are ambiguous, this study is determined to identify the application of barbed suture during PN.

Methods: ClinicalTrials.gov, Cochrane Register of Clinical Studies, PubMed and EMBASE were searched for RCTs(randomized controlled trials) and cohort studies focusing on the comparison of barbed and traditional sutures in PN(last updated on Feb in 2015). According to Cochrane Library's suggestion, quality assessment was performed. Review Manager was applied to analyze all the data and sensitivity analyses were performed through omitting each study sequentially.

Results: Eight cohort studies and none of RCTs proved eligible (risk of bias: moderate to low,431 patients). Warm ischemia time $(\mathrm{MD}=-6.55,95 \% \mathrm{Cl}-8.86$ to $-4.24, P<0.05)$ decreased statistically in the barbed suture group, as well as operative time $(\mathrm{MD}=-11.29,95 \% \mathrm{Cl}-17.87$ to-4.71, $P<0.05)$. Postoperative complications also reduced significantly $(\mathrm{OR}=0.44,95 \% \mathrm{Cl} 0.24$ to $0.80, P<0.05)$. Unidirectional barbed suture resulted in fewer postoperative complications based on the subgroup analysis( $\mathrm{OR}=0.48,95 \% \mathrm{Cl} 0.24$ to $0.94, P<0.05)$.

Conclusions: The barbed suture may be a useful surgical innovation which can modify perioperative results for surgeons and patients. Randomly-designed studies with longer follow up and larger sample sizes are in the need of to explore the applicability.
\end{abstract}

Keywords: Partial nephrectomy, Surgical technique, Systematic review

\section{Background}

Partial nephrectomy (PN) is regarded as the golden standard treatment for small-localized renal tumors currently [1]. With the development of the surgical technology, larger (until $7 \mathrm{~cm}$ and more) cases may also be the appropriate candidates. Type of resection, type of suture

\footnotetext{
* Correspondence: michael_huangjin@163.com; 125798620@qq.com; wangkj@scu.edu.cn

${ }^{\dagger}$ Yifei Lin and Banghua Liao contributed equally to this work.

${ }^{3}$ West China Hospital, Sichuan University, Guoxuexiang 37, Chengdu 610041, Sichuan, China

${ }^{1}$ Department of Urology, Institute of Urology (Laboratory of Reconstructive Urology), West China Hospital, Sichuan University, Chengdu, Sichuan, People's Republic of China

Full list of author information is available at the end of the article
}

and the change of renal function usually play a significant role during the perioperative period of $\mathrm{PN}$ [2]. Generally, warm ischemia time (WIT), among many factors to predict renal function, is the only predictor that can be modified by the surgeon or surgical techniques [3-5]. Though several surgical and technological innovations have been invented to enhance the efficiency of renorrhaphy and decrease WIT, such as the application of hemostatic agents, or even the involvement of the robot assistance [6, 7], different approaches still had their own advantages and disadvantages.

Recently, an innovative of absorbable, the knotless barbed suture is applied for renal pelvicaliceal or/and parenchymal repair to diminish WIT in laparoscopic 
partial nephrectomy [8]. Initiated in 1964 [9], this approach has been first reported in gynaecological and plastic surgery previously [10]. And then some systematic reviews, in terms of radical prostatectomy [11-13], have confirmed equivalence of biocompatibility and tensile strength of knotless barbed suture compared to conventional sutures in urological field [14, 15].

Since partial nephrectomy was one of the earliest urological surgeries that adopted this advanced technology, various effects were reported. Nevertheless, the effect of length of intraoperative ischemia on renal function and life quality of patients after PN is a subject of significantly heated discussion. Thus, a meta-analysis and systematic review was carried out for a more validated result on the application of knotless barbed sutures in $\mathrm{PN}$ comparing with the conventional sutures.

\section{Methods}

\section{Study selection}

A comprehensive literature search, which addressed the topic of barbed suture in partial nephrectomy ("barbed" OR "knotless" AND "suturing" OR "suture") was performed. The databases includede Cochrane Register of Clinical Studies, MEDLINE, EMBASE and clinical trials registered in Clinicaltrials.gov. Available studies from inception to Feb. 21st, 2015 were evaluated for inclusion.

Randomized controlled trials (RCTs) or observational controlled studies reporting comparative outcomes of patients underwent partial nephrectomy using conventional suture or barbed suture were considered for inclusion. Excluded studies included patients using other materials to compare with barbed suture like mesh or staple rather than continues smooth sutures. Studies, including reviews, abstracts, overlapped studies and those published in languages other than English, were also excluded.

\section{Data extraction and outcome measures}

Search results were entered into a bibliographic software (EndNote X7) for further analysis. Two individual investigators (YL, SL) screened all titles and abstracts collected from the search strategy for relevance and full text review.. Extracted data included family name of the first author, publication year, original country, sample sizes, study design, and postoperative complications.

Warm ischemia time, operative time, estimated blood loss or change in hemoglobin level, perioperative blood transfusion, changes in renal function, hospital stay and postoperative complications were considered to be the main outcome measures for the meta-analysis. We also evaluated the heterogeneity of the outcomes to confirm the appropriateness of pooling studies.

\section{Outcome definition}

Operative time was defined as the total time of surgery. Warm ischemia time was determined from the minute of hilar clamping until the moment of unclamping which was the main procedure of partial nephrectomy. Estimated blood loss, change in hemoglobin level and perioperative blood transfusion were defined as the loss of blood during the surgery and it was generally acquired from the surgeons' operative reports or/and anesthesia records. After surgeries, postoperative complications of the suture and hospital stay were also recorded. We specially evaluated the postoperative complications based on the modified Clavien classification [16]. Renal function, including serum creatinine $(\mathrm{sCr})$ and estimated glomerular filtration rate (eGFR), were measured using different measurement tools, for instance, CKD-Epi and RENAL nephrometry score system.

\section{Quality assessment}

Two authors (YL, SL) independently assessed the quality of each included study. Discrepancies were resolved by discussion and a consensus decision. For RCTs, the Cochrane risk of bias tools were used. Observational studies were evaluated using the Newcastle-Ottawa Scale to assess the risk of bias [17]. We included several categories for cohort studies: ascertainment of partial nephrectomy, representativeness of the barbed suture cohort, ascertainment of exposure to barbed suture, selection of the non-exposed cohort, demonstration that outcome of interest (i.e. warm ischemia time) was not reported at the beginning of study, comparability of study controls for important factors (e.g. adequate adjustment for confounders or matching for important confounding factors), assessment of outcome (e.g. adjudication and blinding assessment), and completeness of the follow up.

\section{Statistical analysis}

Results for each study were calculated using a fixed effects model. (random effects mode for high heterogeneity) The existence of statistical heterogeneity was evaluated through the $\mathrm{X}^{2}$ test and $\mathrm{I}^{2}$ test. Pooled standardized mean difference (SMD) and mean difference (MD)are estimated to evaluate the continuous data, and the pooled odds ratios (ORs) were calculated for the evaluation of dichotomous data through Review Manager (Version 5.3). Sub group meta-analysis was performed based on different barbed suture (unidirectional and bidirectional barbed suture). Sensitivity analyses were also performed. $P<0.05$ was considered significant.

\section{Results}

Study selection process and characteristics

A total of 8 cohort studies [18-25] (431 patients), and no RCTs proved eligible. A flow diagram of the detailed 
selection process is reported (Fig. 1). Table 1 shows the baseline characteristics and the results of all the eligible studies. All the data were comparable. Results of combined data comparing barbed suture versus conventional suture are presented in Table 2.

Low to moderate risk of bias were considered among all the included studies (Additional file 1: Table S1). Specifically, the participant population within a study was identified from a same clinical setting comparing barbed suture with control. Ascertainment of patients performed partial nephrectomy was based on surgical records. A total of 3 studies have adjusted important confounding factors by matching pairs (body mass index and operative approach). No loss to follow-up in all studies.
Warm ischemia time

Of the 8 cohort studies, 5 reported the warm ischemia time of partial nephrectomy [18-20, 22, 25] (Fig. 2a). Due to the fact that the heterogeneity is high among the WIT $\left(P=0.09, \mathrm{I}^{2}=50 \%\right)$, the random effects model was adopted instead of the fixed effects model. The pooling of raw data of these 283 cases suggested that patients with barbed suture versus conventional suture had a significantly shorter WIT. (MD $=-6.55,95 \%$ CI -8.86 to -4.24 , $P<0.00001)$. Since Zondervan's study recruited both laparoscopic and open surgeries whereas others only focused on laparoscopic partial nephrectomy, it was excluded for a sensitivity analysis. Therefore, the newly pooled results (221 cases) with low heterogeneity $\left(\mathrm{I}^{2}=0 \%\right.$,) indicated that

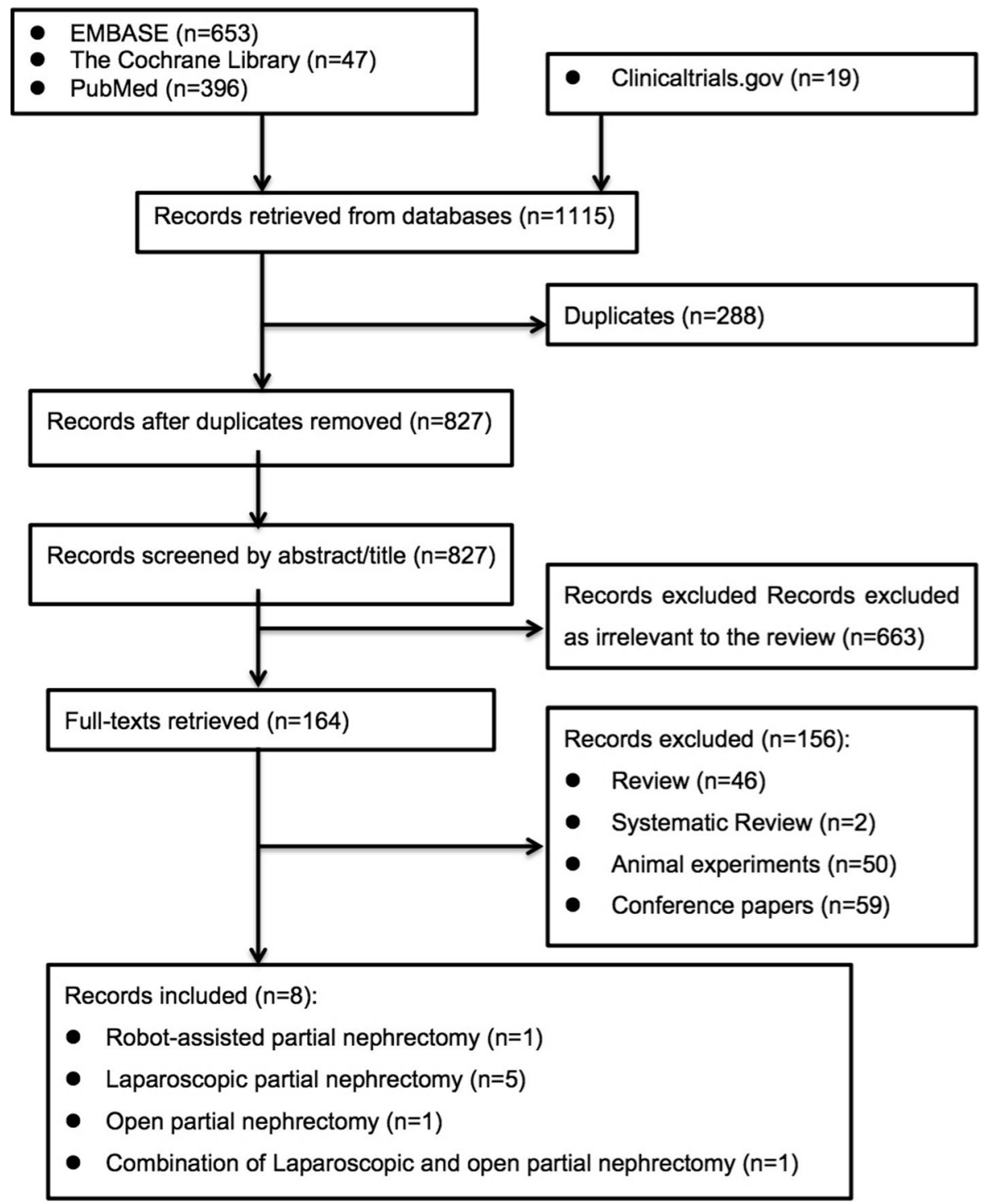

Fig. 1 Flow diagram of the detailed selection process 


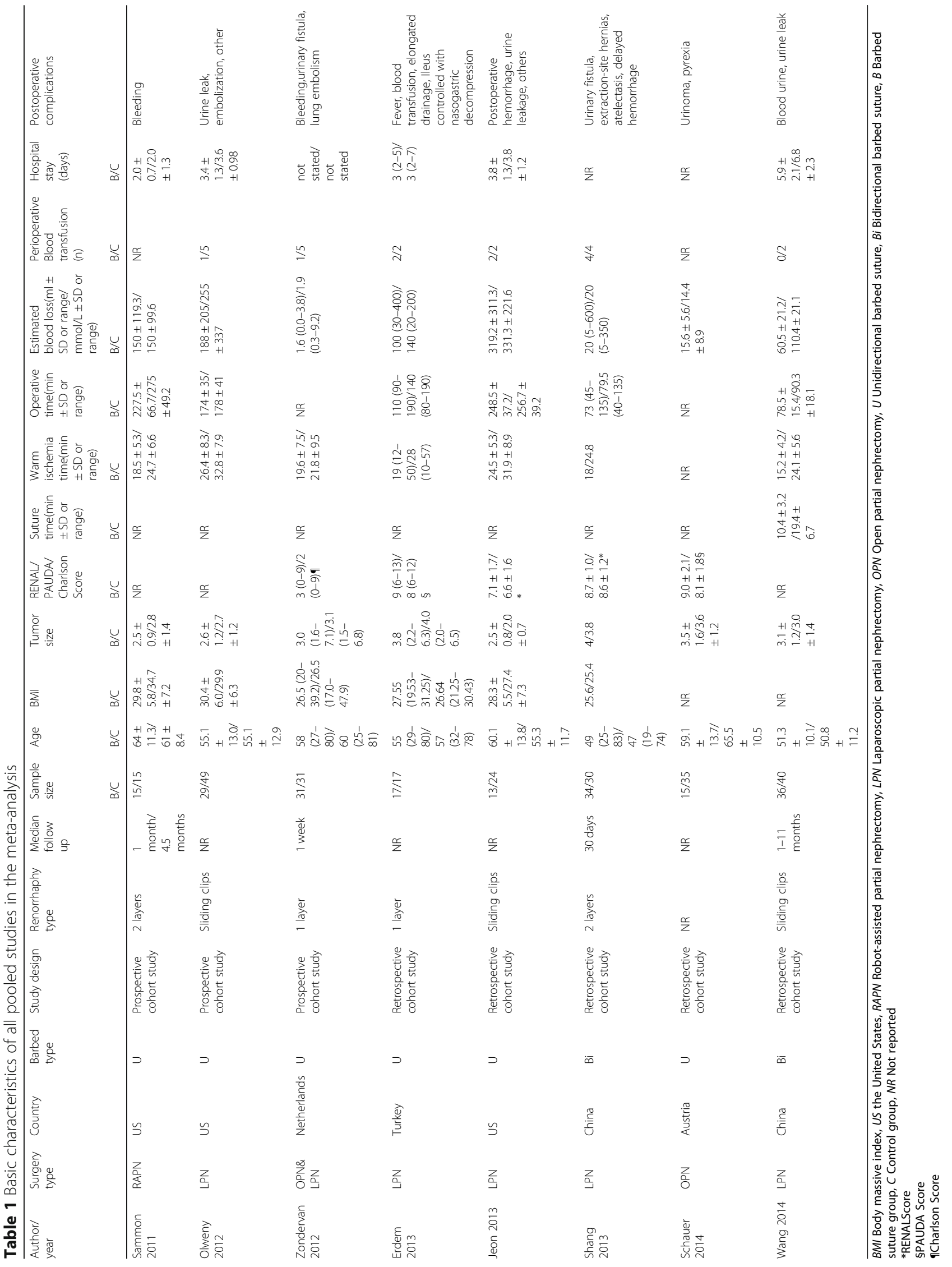


Table 2 Results of meta-analysis comparing barbed and control suture group

\begin{tabular}{|c|c|c|c|c|c|c|c|c|}
\hline \multirow[t]{2}{*}{ Outcomes of interest } & \multicolumn{6}{|c|}{ Results of the combined studies } & \multicolumn{2}{|c|}{$\begin{array}{l}\text { Study } \\
\text { heterogeneity }\end{array}$} \\
\hline & $\begin{array}{l}\text { Studies } \\
\text { no. }\end{array}$ & $\begin{array}{l}\text { Barbed group patients } \\
\text { no. }\end{array}$ & $\begin{array}{l}\text { Control group patient } \\
\text { no. }\end{array}$ & $\begin{array}{l}\text { SMD/MD/ } \\
\text { OR }\end{array}$ & $95 \% \mathrm{Cl}$ & $P$ value & $P^{2}$ & $P$ value \\
\hline Warm ischemia time & 5 & 124 & 159 & -6.55 & -8.86 to -4.24 & $\begin{array}{l}< \\
0.00001\end{array}$ & $50 \%$ & 0.09 \\
\hline Warm ischemia time* & 4 & 93 & 128 & -7.85 & -9.48 to- 6.22 & $\begin{array}{l}< \\
0.00001\end{array}$ & $0 \%$ & 0.56 \\
\hline Operative time & 4 & 93 & 128 & -11.29 & $\begin{array}{l}-17.87 \text { to }- \\
4.71\end{array}$ & 0.0008 & $17 \%$ & 0.30 \\
\hline Estimated blood loss & 5 & 108 & 163 & 0.50 & -1.41 to 0.42 & 0.29 & $91 \%$ & $\begin{array}{l}< \\
0.00001\end{array}$ \\
\hline Estimated blood loss* & 4 & 72 & 123 & -0.07 & -0.36 to 0.23 & 0.66 & $0 \%$ & 0.81 \\
\hline $\begin{array}{l}\text { Perioperative blood } \\
\text { transfusion }\end{array}$ & 6 & 160 & 191 & 0.56 & 0.26 to 1.24 & 0.15 & $0 \%$ & 0.58 \\
\hline Hospital stay & 4 & 93 & 128 & -0.21 & -0.58 to 0.15 & 0.26 & $0 \%$ & 0.49 \\
\hline Postoperative complications & 8 & 190 & 241 & 0.44 & 0.24 to 0.80 & 0.007 & $0 \%$ & 0.92 \\
\hline
\end{tabular}

Cl Confidence Interval, SMD Standardized Mean Deviation, MD Mean Deviation *Sensitive analysis

WIT in laparoscopic partial nephrectomy significantly decreased. $(\mathrm{MD}=-7.85,95 \% \mathrm{CI}-9.48$ to-6.22, $P<0.00001$, Additional file 1: Figure S1).

\section{Operative time}

Four studies of the laparoscopic partial nephrectomy reported data of operative time [18, 19, 22, 25] (Fig. 2b). The pooling of raw data presented a statistically significant association between the suture types (barbed sutures vs. conventional sutures) and operative time based on 221 cases $(\mathrm{MD}=-11.29, P=0.0008,95 \% \mathrm{CI}-17.87$ to -4.71$)$ with low heterogeneity $\left(\mathrm{I}^{2}=17 \%\right)$.

\section{Estimated blood loss}

Five studies reported outcomes of estimated blood loss $[18,19,22,24,25]$ (hemoglobin level or volume of blood loss). (Figure 2c) The pooling outcomes of the 271 cases did not present significantly benefits of barbed suture over conventional suture $(\mathrm{SMD}=-0.50,95 \% \mathrm{CI}-1.41$ to $0.42, P=0.29)$. This finding was, however, highly limited due to a very high level of heterogeneity with random effect model $\left(\mathrm{I}^{2}=91 \%\right)$.

Since Wang's study [25] account for the bidirectional barbed suture (Quill SRS), while others applied unidirectional barbed suture (V-Loc $\left.{ }^{\mathrm{TM}} 180\right)$, we therefore excluded this study for a sensitivity analysis. And the newly pooled results (195 cases) showed the same result while with low heterogeneity. (SMD $=-0.07,95 \% \mathrm{CI}-0.36$ to 0.23 , $P=0.66, \mathrm{I}^{2}=0 \%$, Additional file 1: Figure S2).

\section{Perioperative blood transfusion}

Six studies reported data of perioperative blood transfusion based on 351 participants. [19-23, 25]
(Fig. 2d). Pooling of these cohort studies did not suggest a statistically significant association between the suture types and perioperative blood transfusion $\left(\mathrm{OR}=0.56,95 \%\right.$ CI 0.26 to $\left.1.24, P=0.15, \mathrm{I}^{2}=0 \%\right)$. Moreover, subgroup analysis presented similar results, regardless of unidirectional or bidirectional barbed suture. (Additional file 1: Figure S3).

\section{Hospital stay}

Four studies, with 221 patients recruited, reported about hospital stay [18, 19, 22, 25] (Fig. 2e). Pooling of those outcomes did not present a statistically significant association between the application of barbed suture and hospital duration. (MD $=-0.21,95 \% \mathrm{CI}$ -0.58 to $\left.0.15, P=0.26, \mathrm{I}^{2}=0 \%\right)$.

\section{Postoperative complications}

Eight cohort studies reported raw event data postoperative complications [18-25] and the postoperative complications were evaluated based on the modified Clavien classification(Fig. 2f, Table 1) Pooling data of all the 431 cases showed that significantly fewer postoperative complications were found in patients with barbed suture versus conventional suture. $\left(\mathrm{OR}=0.44, P=0.007,95 \% \mathrm{CI} 0.24\right.$ to $0.80, \mathrm{I}^{2}$ $=0 \%$ ). Then the subgroup analyses (Additional file 1: Figure S4) by barbed suture types showed: compared with unidirectional barbed suture $\left(\mathrm{V}-\mathrm{Loc}^{\mathrm{Tm}}\right)$, the use of barbed suture statistically decreases the postoperative complications. (OR $=0.48,95 \% \mathrm{CI} 0.24$ to $0.94, P=0.03, \mathrm{I}^{2}=0 \%$ ); as for bidirectional barbed suture (Quill SRS), pooled data did not show significant differences between both groups $(\mathrm{OR}=0.35$, $95 \%$ CI 0.10 to $1.18, P=0.09, \mathrm{I}^{2}=0 \%$ ). 

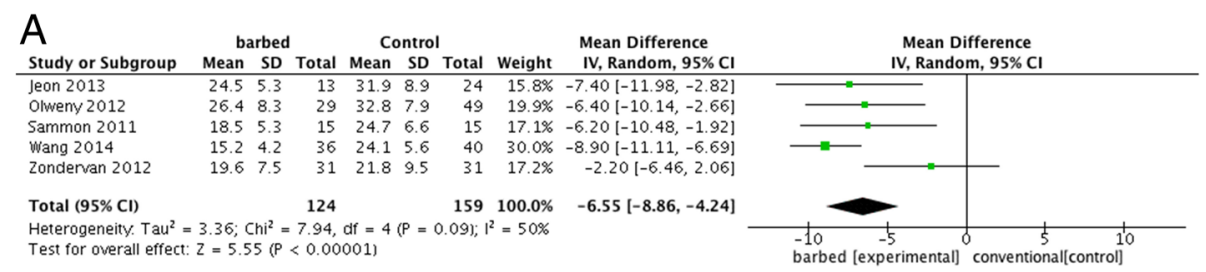

B

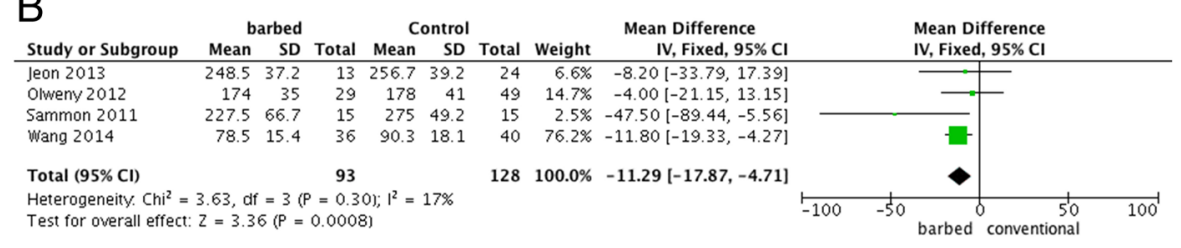

C

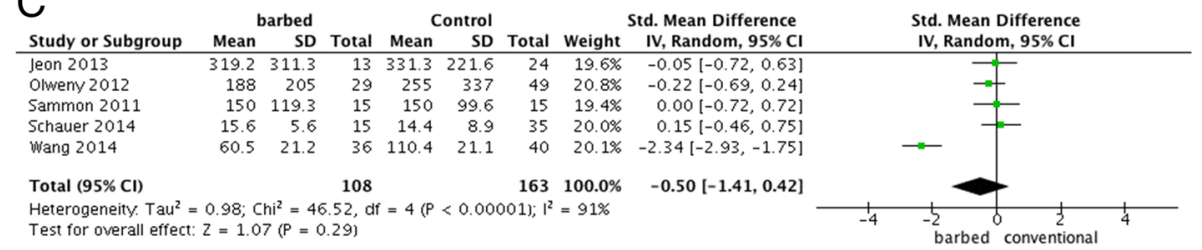

D

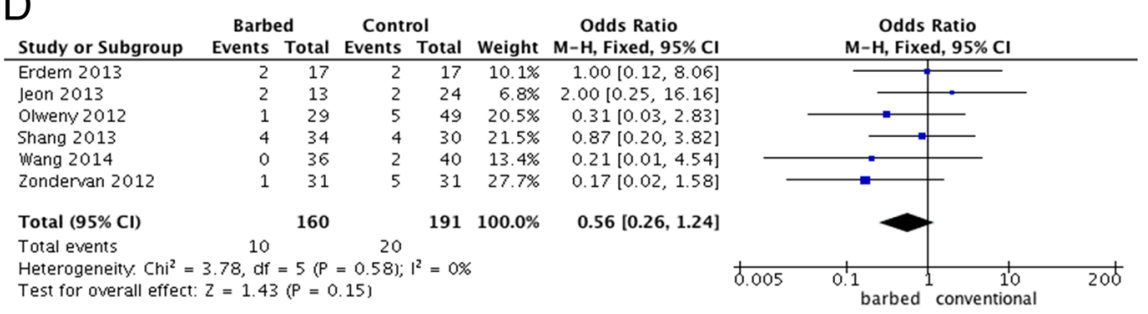

E

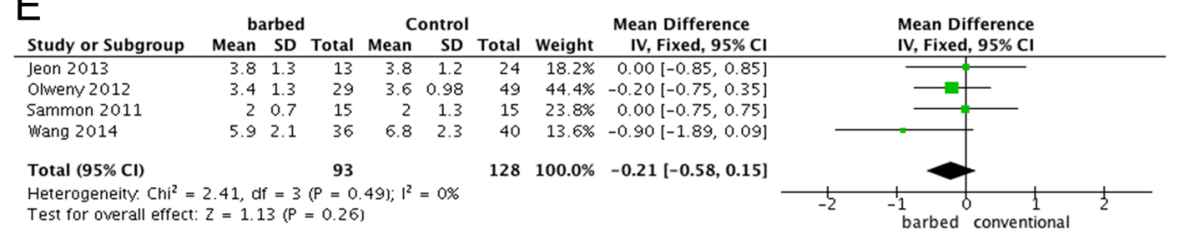

F

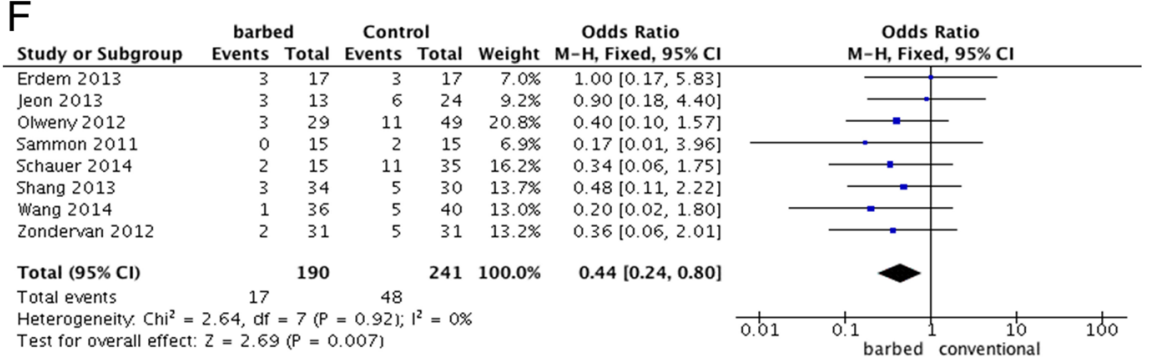

Fig. 2 Pooled estimate of outcomes: (a) A forest plot of warm ischemia time with or without barbed suture; (b) A forest plot of operative time with or without barbed suture; (c) A forest plot of estimated blood loss with or without barbed suture; (d) A forest plot of perioperative blood transfusion with or without barbed suture; (e) A forest plot of hospital stay with or without barbed suture; (f) A forest plot of postoperative complications with or without barbed suture

\section{Changes in renal function}

As the reflection of renal function, sCr and/or eGFR were reported by four studies $[20,21,23,24]$ (Table 3). Measurement tools differed among four studies and only median and range data were reported. Though not readily for pooling, all did not suggest that significant changes between two suture groups in terms of both renal function indicators. 
Table 3 Changes in renal function before and after PN (sCr \& eGFR)

\begin{tabular}{|c|c|c|c|c|c|c|c|c|}
\hline $\begin{array}{l}\text { Author/ } \\
\text { year }\end{array}$ & Surgery & Cohort & N & $\begin{array}{l}\text { Increase in } \mathrm{SCr} \\
\text { umol/L median } \\
\text { [range] }\end{array}$ & $P$ & $\begin{array}{l}\text { Decline in eGFR } \\
\mathrm{ml} / \mathrm{min} / 1.73 \mathrm{~m}^{2} \\
\text { median [range] }\end{array}$ & $P$ & Measurement tools \\
\hline \multirow[t]{2}{*}{$\begin{array}{l}\text { Zondervan } \\
2012\end{array}$} & \multirow[t]{2}{*}{$\begin{array}{l}\text { OPN \& } \\
\text { LPN }\end{array}$} & Barbed & 31 & $\begin{array}{l}10.0(- \\
70.7 \text { to1 14.0) }\end{array}$ & \multirow[t]{2}{*}{0.970} & $0.0(-4.3$ to 14.2$)$ & \multirow{2}{*}{0.735} & \multirow{2}{*}{$\begin{array}{l}\text { Creatinine was measured in the pre and postoperative } \\
\text { period. Pre and postoperative estimated GFR were } \\
\text { calculated using the CKD Epidemiology Collaboration (CKD- } \\
\text { Epi) glomerular filtration equation }\end{array}$} \\
\hline & & Control & 31 & $8.8(-26.5$ to 123.8$)$ & & $0.0(-4.6$ to 18.6$)$ & & \\
\hline \multirow{2}{*}{$\begin{array}{l}\text { Erdem } \\
2013\end{array}$} & \multirow[t]{2}{*}{ LPN } & Barbed & 17 & $0(-0.3$ to2.3) & \multirow[t]{2}{*}{0.190} & $0(-23.0$ to39.0) & \multirow[t]{2}{*}{0.176} & \multirow{2}{*}{$\begin{array}{l}\text { Functional renal preservation was assessed through the } \\
\text { comparison of pre-operative and early postoperative eGFR, } \\
\text { which was calculated using the Chronic Kidney Disease } \\
\text { Epidemiology Collaboration formula. The early postoperative } \\
\text { eGFR was based on an sCr measurement obtained after the } \\
\text { peak sCr within the first } 3 \text { days of surgery. }\end{array}$} \\
\hline & & Control & 17 & $0.1(-0.1$ to 0.6$)$ & & $9.0(-12$ to62) & & \\
\hline \multirow[t]{2}{*}{$\begin{array}{l}\text { Shang* } \\
2013\end{array}$} & \multirow[t]{2}{*}{ LPN } & Barbed & 34 & $\begin{array}{l}2.59(-4.0 \text { to } \\
159.2)\end{array}$ & \multirow[t]{2}{*}{0.797} & $7.7(-35.9 t 041.1)$ & \multirow[t]{2}{*}{0.065} & \multirow[t]{2}{*}{ RENAL nephrometry score system } \\
\hline & & Control & 30 & $\begin{array}{l}2.65(-21.0 \text { to } \\
70.7)\end{array}$ & & $8.9(-30.6$ to37.0) & & \\
\hline \multirow[t]{2}{*}{$\begin{array}{l}\text { Schauer } \\
2014\end{array}$} & \multirow[t]{2}{*}{ OPN } & Barbed & 15 & $\begin{array}{l}20.1(-13.9 \text { to } \\
51.9)\end{array}$ & \multirow[t]{2}{*}{0.33} & 21.2(-18.0to38.0) & \multirow[t]{2}{*}{0.38} & \multirow{2}{*}{$\begin{array}{l}\text { Postoperative changes in renal function parameters, serum } \\
\text { creatinine levels, and eGFRs after surgery and before } \\
\text { discharge. }\end{array}$} \\
\hline & & Control & 35 & $\begin{array}{l}10.3(-18.7 \text { to } \\
61.5)\end{array}$ & & $10.5(-26.1$ to 42.5$)$ & & \\
\hline
\end{tabular}

PN partial nephrectomy, LPN laparoscopic partial nephrectomy, OPN open partial nephrectomy, eGFR estimated glomerular filtration rate, $s C r$ serum creatinine *The time point for renal function tests after surgery in this study was one month later after discharge from hospital, while the tests in other studies was right before the discharge from hospital

\section{Discussion}

In this systematic review, we have included all the controlled studies to test the effects of barbed suture on PN. The pooling of all the cohort studies showed significant decreases in WIT, operative time, and postoperative complications in barbed suture group; the quality of included cohort studies was high to moderate. The subgroup analysis suggested that unidirectional barbed suture significantly minimized the postoperative complications, which seems to be safer than the traditional suture.

As the most important factor after partial nephrectomy, the pooled outcome of WIT witnessed an overall significant reduction in barbed suture groups, especially laparoscopic partial nephrectomies. This means barbed suture can effectively reduce the WIT during laparoscopic partial nephrectomies so as to improve the postoperative renal function.

$\mathrm{SCr}$ and eGFR were the most commonly used tools to evaluate renal function after PN [1], but the change of these two indexes were only reported in four studies $[20,21,23,24]$. Since all the raw data suggested no significant shift between both groups, many researchers believed that the results needed larger sample size [24] and longer follow up time to confirm, say at least 5-year follow up [21]. Besides, there are many ways to determine loss of renal function and evaluate the effects of surgery on renal function, such as renal scan and volumetric assessment of the kidney, which were not reported in the articles included [26, 27]. Moreover, as the concentrations of them are enormously influenced by age, gender, muscle mass and so on $[1,3]$, a more convincing way to evaluate renal function loss in the patients, such as renal scintigraphy, needs to be focused on for future studies. Furthermore, the statistical decrease of operative time in barbed group also indicated that barbed suture was effective in partial nephrectomy either by a robot-assisted, laparoscopic, or open technique [28].

With regard to blood issue, both outcomes of estimated blood loss and transfusion were comparable. After performing the sensitivity analysis on the outcomes of estimated blood loss, the heterogeneity dropped from 91 to $0 \%$ with the pooled outcomes of still no significant difference. Similarly, the subgroup analysis of blood transfusion by different barbed suture did not suggest any difference from the overall effect. However, Zondervan et al [20]. reported that no difference was owing to the fact that hemostatic agents applied during surgery were not considered, thus this may be a confounding factor that need take into account in the future.

Meanwhile, number of postoperative complications was significantly minimized in barbed suture groups. Besides, subgroup analysis indicated that unidirectional barbed suture turned out to be safer than the convention suture while bidirectional barbed suture did not. However, no human study concerned the safety and efficacy among different barbed sutures. Thus the feasibility and safety among different barbed sutures in vivo study need to take into consideration $[29,30]$.

The pooled outcome in this study provides a reliable evidence for the relationship between the barbed suture and some important surgical indicators for PN. 
However, there are limitations of this study [1]. Even though two cohort studies adjusted their analyses via matching pairs, the pooled data may also be influenced by many factors, such as surgeons' preference or learning curves due to none of RCTs recruited [2]. Because not all the studies evaluated the tumor via RENAL, PAUDA or Charlson scores before surgeries, it is impossible to perform subgroup analyses based on those indexes and future studies should uniform the standards to evaluate renal tumors [3]. The literatures search was extensive, but the barbed suture only suggested for all $\mathrm{T} 1$ kidney tumors rather than some suitable T2-may be or T3 cases and still did not involve animal studies, letters to the editors, and conference publications; and [4] because only 8 studies were recruited, the risk of publication bias could not be evaluated by the Begg's funnel plots.

Nevertheless, our result renews a latest meta-analysis on barbed suture in PN. Based on what we know, this is to date the most comprehensive meta-analysis and systematic review exploring the relationship between barbed and traditional suture in PN.

\section{Conclusions}

The barbed suture may be a useful surgical innovation which can modify perioperative results for surgeons and patients. Significant decline of suture time, operative time and postoperative complications were found using barbed suture during PN. Unidirectional barbed suture seemed to be safer. Because of the limitations of quality, especially that matched renal tumor complexity is not utilized, this state-of-the-art need to be proved by evidences with higher quality, and randomized-controlled studies with longer follow up and larger sample sizes will be needed to prove the findings of the present studies.

\section{Additional file}

Additional file 1: Figure S1. A forest plot of sensitivity analysis of warm ischemia time with or without barbed suture. Figure S2. A forest plot of sensitivity analysis of Estimate blood loss with or without barbed suture. Figure S3. A forest plot of subgroup analysis of perioperative blood transfusion with or without barbed suture. Figure S4. A forest plot of subgroup analysis of postoperative complications with or without barbed suture. Table S1. Quality assessment of studies in the meta-analysis based on Newcastle-Ottawa Scale (NOS). (DOCX 92 kb)

\section{Acknowledgements}

Supported by Grant No. 81403276 from the National Natural Science Foundation of China and Grant No. JH20140066 from the Technology Support Program of Science and Technology Department of Sichuan Province.

\section{Funding}

Supported by Grant No. 81403276 from the National Natural Science Foundation of China and Grant No. JH20140066 from the Technology Support Program of Science and Technology Department of Sichuan Province. The funders had no role in the experimental design, data collection, analysis, preparation of the manuscript, or decision to publish. Any opinions, findings, conclusions, or recommendations expressed in this article are those of the authors alone, and do not necessarily reflect the views of funders.

Availability of data and materials

All the data supporting your findings is contained within the manuscript.

\section{Authors' contributions}

YL, BL: Project development, data analysis and management, manuscript writing and editing. SL: Data collection, data analysis and management. LD: Data analysis and management, management manuscript writing and editing. $J \mathrm{H}, \mathrm{KW}, \mathrm{HL}$ : project development, manuscript writing and editing. All authors read and approved the final manuscript.

\section{Ethics approval and consent to participate}

Ethics was not required for our meta-analysis. And consent was not required from the patients/guardians as this meta-analysis only concerns patients whose details have already been published.

\section{Consent for publication}

This is not required for a meta-analysis of previously published information.

\section{Competing interests}

The authors report no proprietary or commercial interest in any product or concept discussed in the article.

\section{Publisher's Note}

Springer Nature remains neutral with regard to jurisdictional claims in published maps and institutional affiliations.

\section{Author details}

${ }^{1}$ Department of Urology, Institute of Urology (Laboratory of Reconstructive Urology), West China Hospital, Sichuan University, Chengdu, Sichuan, People's Republic of China. ${ }^{2}$ West China School of Medicine, Sichuan University, Guoxuexiang 37, Chengdu 610041, Sichuan, China. ${ }^{3}$ West China Hospital, Sichuan University, Guoxuexiang 37, Chengdu 610041, Sichuan, China.

Received: 2 August 2017 Accepted: 26 December 2018

Published online: 10 January 2019

\section{References}

1. Volpe A, Blute ML, Ficarra V, Gill IS, Kutikov A, Porpiglia F, et al. Renal ischemia and function after partial nephrectomy: a collaborative review of the literature. Eur Urol. 2015;68(1):61-74.

2. Porpiglia F, Bertolo R, Amparore D, Fiori C. Nephron-sparing suture of renal parenchyma after partial nephrectomy: which technique to go for? Some best practices. Eur Urol Focus. In press.

3. Lane BR, Babineau DC, Poggio ED, Weight CJ, Larson BT, Gill IS, et al. Factors predicting renal functional outcome after partial nephrectomy. J Urol. 2008; 180(6):2363-8 discussion 8-9.

4. Becker F, Van Poppel H, Hakenberg OW, Stief C, Gill I, Guazzoni G, et al Assessing the impact of ischaemia time during partial nephrectomy. Eur Urol. 2009;56(4):625-34

5. Gao ZL, Gu GL, Wu JT, Wang L. Comparison of the transperitoneal and semi-open retroperitoneal approach for right-sided laparoscopic donor nephrectomy. Ann Transplant. 2011;16(4):40-6.

6. Benway BM, Wang AJ, Cabello JM, Bhayani SB. Robotic partial nephrectomy with sliding-clip renorrhaphy: technique and outcomes. Eur Urol. 2009;55(3): 592-9.

7. Gettman MT, Blute ML, Chow GK, Neururer R, Bartsch G, Peschel R. Roboticassisted laparoscopic partial nephrectomy: technique and initial clinical experience with DaVinci robotic system. Urology. 2004;64(5):914-8.

8. Seideman C, Park S, Best SL, Cadeddu JA, Olweny EO. Self-retaining barbed suture for parenchymal repair during minimally invasive partial nephrectomy. J Endourol. 2011:25(8):1245-7 discussion 7-8.

9. Ruff GL. The history of barbed sutures. Aesthet Surg J. 2013;33(3 Suppl):12s-6s.

10. Warner JP, Gutowski KA. Abdominoplasty with progressive tension closure using a barbed suture technique. Aesthet Surg J. 2009;29(3):221-5.

11. Bai Y, Pu C, Yuan H, Tang Y, Wang X, Li J, et al. Assessing the impact of barbed suture on Vesicourethral anastomosis during minimally invasive 
radical prostatectomy: a systematic review and meta-analysis. Urology. 2015; 85(6):1368-75.

12. Li H, Liu C, Zhang H, Xu W, Liu J, Chen Y, et al. The use of unidirectional barbed suture for Urethrovesical anastomosis during robot-assisted radical prostatectomy: a systematic review and meta-analysis of efficacy and safety. PLoS One. 2015;10(7):e0131167.

13. Lin YF, Lai SK, Liu QY, Liao BH, Huang J, Du L, et al. Efficacy and safety of barbed suture in minimally invasive radical prostatectomy: a systematic review and meta-analysis. Kaohsiung J Med Sci. 2017;33(3):107-15.

14. Weld KJ, Ames CD, Hruby G, Humphrey PA, Landman J. Evaluation of a novel knotless self-anchoring suture material for urinary tract reconstruction. Urology. 2006;67(6):1133-7.

15. Rashid RM, Sartori M, White LE, Villa MT, Yoo SS, Alam M. Breaking strength of barbed polypropylene sutures: rater-blinded, controlled comparison with nonbarbed sutures of various calibers. Arch Dermatol. 2007:143(7):869-72.

16. Dindo D, Demartines N, Clavien PA. Classification of surgical complications: a new proposal with evaluation in a cohort of 6336 patients and results of a survey. Ann Surg. 2004;240(2):205-13.

17. Wells GA, Shea B, Peterson JEA, Welch V, Losos M, Tugwell P. The NewcastleOttawa scale (NOS) for assessing the quality of nonrandomised studies in meta-analyses; 2000.

18. Sammon J, Petros F, Sukumar S, Bhandari A, Kaul S, Menon M, et al. Barbed suture for renorrhaphy during robot-assisted partial nephrectomy. J Endourol. 2011;25(3):529-33.

19. Olweny EO, Park SK, Seideman CA, Best SL, Cadeddu JA. Self-retaining barbed suture for parenchymal repair during laparoscopic partial nephrectomy; initial clinical experience. BJU Int. 2012;109(6):906-9.

20. Zondervan PJ, Gozen AS, Opondo D, Rassweiler JJ, de la Rosette JJ, Laguna MP. Partial nephrectomy: is there an advantage of the self-retaining barbed suture in the perioperative period? A matched case-control comparison. World J Urol. 2012;30(5):659-64

21. Erdem S, Tefik T, Mammadov A, Ural F, Oktar T, Issever H, et al. The use of self-retaining barbed suture for inner layer renorrhaphy significantly reduces warm ischemia time in laparoscopic partial nephrectomy: outcomes of a matched-pair analysis. J Endourol. 2013;27(4):452-8.

22. Jeon SH, Jung S, Son HS, Kimm SY, Chung Bl. The unidirectional barbed suture for renorrhaphy during laparoscopic partial nephrectomy: Stanford experience. J Laparoendosc Adv Surg Tech A. 2013;23(6):521-5.

23. Shang JW, Ma X, Zhang X, Li HZ, Shi TP. Comparison of two different renorrhaphy techniques in retroperitoneal laparoscopic partial nephrectomy for complex tumor. Chin Med J. 2013;126(24):4629-32.

24. Schauer I, Theimer O, Klatte T, Waldert M, Klingler HC, Margreiter M. Use of self-retaining barbed sutures decreases cold ischemia time in open nephronsparing surgery. Wien Klin Wochenschr. 2014;126(11-12):329-34.

25. Wang $K$, Zhang $Y L$, Lin CH, Liu DF, Men CP, Wang JM, et al. Application of self-retaining bidirectional barbed absorbable suture in retroperito- neoscopic partial nephrectomy. Int Braz J Urol. 2014;40(2):220-4.

26. Porpiglia F, Bertolo R, Fiori C. Words of wisdom: re: residual parenchyma volume, not warm ischemia time, predicts ultimate renal functional outcomes in patients undergoing partial nephrectomy. Eur Urol. 2016;69(1):176-7.

27. Bertolo RG, Zargar H, Autorino R, Fiori C, Kaouk JH, Russo P, et al. Estimated glomerular filtration rate, renal scan and volumetric assessment of the kidney before and after partial nephrectomy: a review of the current literature. Minerva Urol Nefrol. 2017;69(6):539-47.

28. Campbell SC, Novick AC, Belldegrun A, Blute ML, Chow GK, Derweesh IH, et al. Guideline for management of the clinical T1 renal mass. J Urol. 2009; 182(4):1271-9.

29. Jordan MC, Holscher-Doht $\mathrm{S}$, Jakubietz MG, Jakubietz RG, Meffert RH, Schmidt K. Suture material for flexor tendon repair: 3-0 V-Loc versus 3-0 Stratafix in a biomechanical comparison ex vivo. J Orthop Surg Res. 2014:9:72

30. lavazzo C, Mamais I, Gkegkes ID. The role of knotless barbed suture in gynecologic surgery: systematic review and meta-analysis. Surg Innov. 2014:528-39.

\section{Ready to submit your research? Choose BMC and benefit from:}

- fast, convenient online submission

- thorough peer review by experienced researchers in your field

- rapid publication on acceptance

- support for research data, including large and complex data types

- gold Open Access which fosters wider collaboration and increased citations

- maximum visibility for your research: over $100 \mathrm{M}$ website views per year

At $\mathrm{BMC}$, research is always in progress.

Learn more biomedcentral.com/submissions 